\title{
Detoxification of hemicellulosic hydrolysates from extracted olive pomace by diananofiltration
}

\author{
Teresa Brás ${ }^{a, b}$, Vera Guerra $^{c}$, Ivone Torrado ${ }^{c}$, Pedro Lourenço $^{d}$, Florbela Carvalheiro ${ }^{c}$, \\ Luís C. Duarte ${ }^{\mathrm{c}}$, Luísa A. Neves ${ }^{\mathrm{a}, \mathrm{e}, *}$ \\ a Centro de Biotecnologia Agrícola e Agro-Alimentar do Baixo Alentejo e Litoral (CEBAL)/Instituto Politécnico de Beja (IPBeja), 7801-908 Beja, Portugal \\ b CICECO, University of Aveiro, 3810-193 Aveiro, Portugal \\ ' Unidade de Bioenergia-LNEG, Ed. K2, Estrada do Paço do Lumiar, 22, 1649-038 Lisboa, Portugal \\ d UCASUL, Rua Mira Fernandes, 2, 7801-901 Beja, Portugal \\ e REQUIMTE/CQFB, FCT, Universidade Nova de Lisboa, Campus de Caparica, 2829-516 Caparica, Portugal
}

\section{A R T I C L E I N F O}

\section{Article history:}

Received 6 June 2013

Received in revised form

10 September 2013

Accepted 11 September 2013

Available online 25 September 2013

\section{Keywords:}

Nanofiltration

Diafiltration

Hydrolysate detoxification

Fermentation inhibitors

Sustainable membrane processing

\begin{abstract}
A B S T R A C T
Xylitol can be obtained from the pentose-rich hemicellulosic fraction of agricultural residues, such as extracted olive pomace, by fermentation. Dilute acid hydrolysis of lignocellulosic materials, produces the release of potential inhibitory compounds mainly furan derivatives, aliphatic acids, and phenolic compounds. In order to study the potential on the increase of the hydrolysate fermentability, detoxification experiments based on diananofiltration membrane separation processes were made. Two membranes, NF270 and NF90, were firstly evaluated using hydrolysate model solutions under total recirculation mode, to identify the best membrane for the detoxification. NF270 was chosen to be used in the diananofiltration experiment as it showed the lowest rejection for toxic compounds and highest permeate flux. Diananofiltration experiments, for hydrolysate model solutions and hydrolysate liquor, showed that nanofiltration is able to deplete inhibitory compounds and to obtain solutions with higher xylose content. Conversely to non-detoxified hydrolysates, nanofiltration detoxified hydrolysates enabled yeast growth and xylitol production by the yeast Debaryomyces hansenii, clearly pointing out that detoxification is an absolute requirement for extracted olive pomace dilute acid hydrolysate bioconversion.
\end{abstract}

(c) 2013 Elsevier Ltd. All rights reserved.

\section{Introduction}

In the Mediterranean area, olive tree is a very widespread cultivar, and olives represent one of the most important agriculture products [1-3]. In the Mediterranean area, the production of olives has been estimated at $7.8 \times 10^{6}$ ton [4] where olive pomace represents approximately $35 \%(\mathrm{w} / \mathrm{w})$ of the processed olives [1]. This material can undergo solvent extraction to yield olive pomace oil and extracted olive pomace. The later, has no significant industrial use and must be upgrade. Likewise, to other agro-food residues, it is a lignocellulosic residue, whose hemicellulose fraction yields significant amounts of xylose, under acidic conditions.

The resulting liquid phase from acid hydrolysis, the hemicellulosic hydrolysate, can be used in fermentation media suitable for xylitol production [5], a commercial polyol with many applications in food, cosmetics and pharma industries [6].

\footnotetext{
* Corresponding author at: REQUIMTE/CQFB, FCT, Universidade Nova de Lisboa, Campus de Caparica, 2829-516 Caparica, Portugal. Tel.: +351 212948385; fax: +351 212948550 .

E-mail address: lan11892@fct.unl.pt (L.A. Neves).
}

During acid hydrolysis, several fermentation inhibiting and toxic compounds are also released and produced. These compounds may be divided in three groups, namely, furan derivatives, aliphatic acids and phenolic compounds [7-10]. Furans, furfural and hydroxymethylfurfural (HMF), are the result of pentose and hexose degradation during hydrolysis. Both can inhibit cells affecting mainly the duration of the lag phase $[11,12]$. Formic and levulinic acids are formed from furans degradation [10] and together with the quantitatively more relevant acetic acid, derived from the release of acetyl groups present in the hemicelluloses, are the main aliphatic acids present. Their inhibitory potential varies depending on the concentration of the undissociated form and cultivation conditions employed in the fermentative process [5,9-11]. Phenolic compounds, derived both from extractives or from lignin degradation, have also a potential inhibitory effect on the fermentation of lignocellulosic hydrolysates, causing a partition and loss of integrity of biological membranes [8]. All these compounds can also interact synergistically with each other, further stressing the fermentation [13-15].

In order to remove the inhibitors and increase the hydrolysate fermentability, several detoxification treatments have already been studied $[7,10]$. The main option is typically the use of over-liming 